\title{
Adjunctive long-acting risperidone in patients with bipolar disorder who relapse frequently and have active mood symptoms
}

\author{
Wayne Macfadden ${ }^{1}$, Caleb M Adler², Ibrahim Turkoz ${ }^{3}$, John T Haskins ${ }^{3}$, Norris Turner ${ }^{4}$ and Larry Alphs ${ }^{4 *}$
}

\begin{abstract}
Background: The objective of this exploratory analysis was to characterize efficacy and onset of action of a 3month treatment period with risperidone long-acting injection (RLAI), adjunctive to an individual's treatment regimen, in subjects with symptomatic bipolar disorder who relapsed frequently and had significant symptoms of mania and/or depression.
\end{abstract}

Methods: Subjects with bipolar disorder with $\geq 4$ mood episodes in the past 12 months entered the open-label stabilization phase preceding a placebo-controlled, double-blind study. Subjects with significant depressive or manic/mixed symptoms at baseline were analyzed. Significant depressive symptoms were defined as MontgomeryÅsberg Depression Rating Scale (MADRS) $\geq 16$ and Young Mania Rating Scale (YMRS) < 16; manic/mixed symptoms were YMRS $\geq 16$ with any MADRS score. Subjects received open-label RLAl (25-50 mg every 2 weeks) for 16 weeks, adjunctive to a subject's individualized treatment for bipolar disorder (mood stabilizers, antidepressants, and/or anxiolytics). Clinical status was evaluated with the Clinical Global Impressions of Bipolar Disorder-Severity (CGI-BP-S) scale and changes on the MADRS and YMRS scales. Within-group changes were evaluated using paired $t$ tests; categorical differences were assessed using Fisher exact test. No adjustment was made for multiplicity.

Results: 162 subjects who relapsed frequently met criteria for significant mood symptoms at open-label baseline; 59/162 (36.4\%) had depressive symptoms, 103/162 (63.6\%) had manic/mixed symptoms. Most subjects (89.5\%) were receiving $\geq 1$ medication for bipolar disorder before enrollment. Significant improvements were observed for the total population on the CGI-BP-S, MADRS, and YMRS scales ( $p<.001$ vs. baseline, all variables). Eighty-two (53.3\%) subjects achieved remission at the week 16 LOCF end point. The subpopulation with depressive symptoms at open-label baseline experienced significant improvement on the CGI-BP-S and MADRS scales ( $p<.001$ vs. baseline, all variables). Subjects with manic/mixed symptoms at baseline had significant improvements on the CGIBP-S and YMRS scales ( $p<.001$ vs. baseline, all variables). No unexpected tolerability findings were observed.

Conclusions: Exploratory analysis of changes in overall clinical status and depression/mania symptoms in subjects with symptomatic bipolar disorder who relapse frequently showed improvements in each of these areas after treatment with RLAl, adjunctive to a subject's individualized treatment. Prospective controlled studies are needed to confirm these findings.

\section{Background}

Bipolar disorder is a serious, lifelong mental illness associated with marked psychosocial disability [1-5]. Although the goal of treatment during an acute episode is symptom control to preserve psychosocial functioning

\footnotetext{
* Correspondence: LAlphs@its.jnj.com

${ }^{4}$ Janssen Scientific Affairs, LLC, Titusville, NJ, USA

Full list of author information is available at the end of the article
}

[6], patients with bipolar disorder who relapse frequently are a difficult-to-treat population $[7,8]$. In many cases, clinicians may initiate treatment with monotherapy; however, therapeutic management often requires the addition of adjunctive medications that can include mood stabilizers, antidepressants, or antipsychotics [6].

A significant barrier to treatment of bipolar disorder is nonadherence. In a sample of outpatients, $24 \%$ of subjects were found to be at least partially nonadherent on

\section{CiolMed Central}


$20 \%$ or more of study visits [9]. Factors that have been associated with poor adherence include history of rapid cycling, bipolar type I disorder, and greater illness severity $[9,10]$. Poor adherence to medication has been associated with a higher rate of recurrence and hospitalization $[11,12]$. Subjects who were adherent at least $75 \%$ of the time were at lower risk for all-cause rehospitalization and mental health-related rehospitalization [12]. Therefore, improving adherence is likely to result in improved treatment outcomes.

Oral antipsychotics are often used adjunctively to treat the symptoms of bipolar disorder, but their effectiveness may be compromised by poor medication adherence. Long-acting injectable atypical antipsychotics may allow clinicians to identify and respond more easily to poor adherence [13]. One long-term, prospective study of acutely manic inpatients with bipolar disorder and a history of poor or partial adherence found that risperidone long-acting injection (RLAI) significantly decreased hospitalization rates and reduced discontinuation of all medications the patients were taking [14]. Further, RLAI as maintenance therapy has been observed to significantly delay time to relapse in subjects with bipolar disorder when used either as monotherapy or as an adjunct to individualized pharmacotherapy in subjects who relapse frequently $[15,16]$.

The objective of this post hoc analysis was to examine clinical, symptomatic, and functional outcomes during the 16-week, open-label phase of an international (United States and India), double-blind, relapse-prevention study examining the addition of adjunctive RLAI to individualized pharmacotherapy in subjects with bipolar disorder who relapsed frequently over the previous 12 months (NCT00094926) [15]. The aim of the analysis was to determine whether the addition of RLAI to individual treatment regimens of mood stabilizers, antidepressants, and/or anxiolytics was beneficial in a subset of subjects from this study who were experiencing depressive or manic/mixed symptoms.

\section{Methods}

\section{Study Design}

This post hoc analysis examined data from the 16-week, open-label stabilization phase that preceded the randomized, double-blind, relapse-prevention phase. The protocol was approved by an institutional review board or ethics committee at each site, and the study was conducted in accordance with current International Conference on Harmonization/World Health Organization Good Clinical Practice guidelines and the Declaration of Helsinki.

\section{Subjects}

Eligible subjects were 18-70 years of age, had bipolar type I or II disorder, diagnosed using the Diagnostic and
Statistical Manual of Mental Disorders, Fourth Edition, Text Revision, and had experienced 4 or more mood episodes requiring psychiatric intervention in the previous 12 months [15]. In the original study, subjects with any degree of mood symptom severity were included. The current analysis focused only on subjects with significant depressive or manic/mixed symptoms at open-label baseline (depressive symptoms: MontgomeryÅsberg Depression Rating Scale [MADRS] [17] $\geq 16$ and Young Mania Rating Scale [YMRS] [18] < 16; manic/ mixed symptoms: YMRS $\geq 16$ with any MADRS score).

\section{Treatment}

RLAI 25 mg every 2 weeks was initiated at open-label baseline, with optional dosage increases to $37.5 \mathrm{mg}$ at week 4 and to $50 \mathrm{mg}$ at week 10 (per the investigators' clinical judgment). Oral antipsychotics that subjects were taking before the study were continued for 3 weeks after the first RLAI injection, and subjects who were not taking oral antipsychotics received oral risperidone. Additional medications for bipolar disorder were individually determined for each subject and could include any number or combination of antidepressants, mood stabilizers, and anxiolytics, with the exception of carbamazepine, oxcarbazepine, fluoxetine, and paroxetine. These medications were initiated, resumed, or changed at the discretion of the investigators at any time during the first 12 weeks of open-label stabilization.

\section{Assessments}

Clinical status was determined by the Clinical Global Impressions of Bipolar Disorder-Severity (CGI-BP-S) scale [19];manic and depressive symptoms were measured using the YMRS and MADRS, respectively. Assessments were performed at baseline and weeks 4, 8, 12 , and 16. Remission was defined as YMRS total score $\leq 8$, MADRS total score $\leq 10$, and CGI-BP-S score $\leq 2$. Functioning was assessed by the Global Assessment of Functioning (GAF) scale [20], conducted at baseline and at week 16. Scores on the GAF scale range from 0 to 100 , with higher scores indicating better functioning. Safety was determined by adverse event (AE) monitoring at each visit.

\section{Statistical Analysis}

Efficacy and safety outcomes were analyzed in subjects enrolled in the open-label phase who received $\geq 1$ dose of RLAI. Demographic and baseline characteristics were summarized using descriptive statistics. Last-observation-carried-forward (LOCF) methodology was used for the YMRS, MADRS, CGI-BP-S, and GAF analyses at end point. Subjects completing 16 weeks of treatment (completers) also were evaluated. A change of $\geq 10$ 
points in the GAF score also was identified. Withingroup changes from open-label baseline were evaluated using paired $t$ tests; categorical differences were assessed by Fisher exact test. All statistical tests were 2-sided, and the nominal type I error was fixed at 0.05 . No adjustments were made for multiplicity.

\section{Results}

Baseline Demographics, Clinical Characteristics, and Disposition

One hundred sixty-two (58.9\%) of the 275 subjects who enrolled in the original study had significant mood symptoms at open-label baseline. Of the 162 subjects, 59 (36.4\%) subjects had significant depressive symptoms and $103(63.6 \%)$ had significant manic/mixed symptoms (Table 1). Of the subjects with current depressive symptoms, $81.4 \%$ were diagnosed with bipolar type I disorder, as were $93.2 \%$ of subjects with manic/mixed symptoms. A higher percentage of symptomatic women (44.3\%) than symptomatic men (30.4\%) had significant depressive symptoms; $69.6 \%$ of symptomatic men and $55.7 \%$ of symptomatic women had significant manic/ mixed symptoms. The most recent episode for $74.6 \%$ of subjects with significant current depressive symptoms was a depressive episode; the most recent episode for $70.9 \%$ of subjects with significant manic/mixed symptoms was a manic episode. Overall, $74.1 \%$ of subjects with significant mood symptoms completed the 16week open-label phase: $74.6 \%$ subjects with depressive symptoms and $73.8 \%$ with manic/mixed symptoms (Table 1).

\section{Bipolar Disorder Medication Use and RLAI Dose}

Most subjects in the total symptomatic population at baseline $(89.5 \%)$ were taking $\geq 1$ medication for bipolar disorder before enrollment; 47 (29.0\%) were receiving oral antipsychotics. For subjects who completed 16 weeks of treatment, with the exception of a higher use of antidepressants compared with baseline (42.5 vs. $29.6 \%$ ), the number of medications taken for bipolar disorder was generally similar at baseline and week 16 (Table 2).

Of depressive and manic/mixed subjects, $91.5 \%$ and $88.3 \%$ at baseline, respectively, were taking $\geq 1$ medication; similar proportions of subjects were taking antipsychotics. At week 16, with the exception of a higher use of antidepressants compared with baseline for the depressive population (63.6\% vs. $44.1 \%)$, the number of medications received for bipolar disorder was generally similar at baseline and week 16 .

The median dose of RLAI during the open-label stabilization phase for all symptomatic subjects was $25 \mathrm{mg}$ every 2 weeks; the mean doses and the dose distributions for the depressive and manic/mixed groups were similar (Table 1).

\section{Total Population of Subjects with Significant Mood Symptoms \\ Efficacy}

The clinical status improved significantly by week 4 and at each subsequent time point, as determined by CGIBP-S total scores (Figure 1). Mood symptoms also improved, as reflected in significant decreases in mean MADRS and YMRS scores for subjects at LOCF end point and for completers (Table 3). Remission was attained by $53.3 \%$ of subjects at LOCF end point and by $61.3 \%$ of completers (Figure 2). A 10-point improvement in GAF score was observed in $62.3 \%$ of subjects at LOCF end point and in $68.9 \%$ of completers, with mean (standard deviation [SD]) GAF scores improving 16.3 $(17.1 ; \mathrm{p}<.001)$ points and $19.0(16.7$; $\mathrm{p}<.001)$ points, respectively (Table 3 ).

\section{Safety}

Safety results were similar to those previously reported [15]. Most (75.3\%) subjects experienced $\geq 1$ AE during this 16-week period. The most common AEs, with an incidence of $\geq 10 \%$, were tremor $(22.8 \%)$, muscle rigidity (15.4\%), weight increase (13.6\%), and headache (11.1\%). Eight percent of the population discontinued because of AEs. At baseline, the mean (SD) weight was 74.1 (20.4) $\mathrm{kg}$. The mean (SD) weight increase from baseline was $2.0(4.1) \mathrm{kg}$ for subjects at LOCF end point and 2.1 (4.4) $\mathrm{kg}$ for completers $(\mathrm{p}<.001 \mathrm{vs}$. baseline for both comparisons).

\section{Subjects with Depressive Symptoms at Baseline Efficacy}

Mean scores significantly improved on the CGI-BP-S by week 4 and each subsequent time point (Figure 1). Remission was achieved by $44.6 \%$ of subjects at LOCF end point and by $56.8 \%$ of completers (Figure 2). Mean MADRS scores decreased significantly at each time point including LOCF end point (Figure 3). A 10-point improvement in GAF score was observed in $56.4 \%$ of subjects at LOCF end point and in $63.6 \%$ of completers, and the mean (SD) change from baseline in GAF scores was $13.0(16.6)(\mathrm{p}<.001)$ and $15.5(16.4)(\mathrm{p}<.001)$, respectively (Table 3 ).

Safety

The proportion of subjects who had $\geq 1$ AE was $69.5 \%$. The most common AEs, with an incidence of $\geq 10 \%$, were tremor $(17.0 \%)$, headache $(13.6 \%)$, muscle rigidity (11.9\%), fatigue $(11.9 \%)$ and somnolence $(10.2 \%)$. The proportion of subjects who discontinued because of AEs was $10.2 \%$. At baseline, the mean (SD) weight was 72.5 (21.2) kg. The mean (SD) weight increase from baseline 
Table 1 Baseline demographic and clinical characteristics, disposition, and RLAl mean daily dose and dose distribution (ITT analysis set)

\begin{tabular}{|c|c|c|c|}
\hline & $\begin{array}{c}\text { Total } \\
(\mathrm{N}=162)\end{array}$ & $\begin{array}{c}\text { Baseline } \\
\begin{array}{c}\text { Depressive Symptoms } \\
(\mathrm{n}=59)\end{array}\end{array}$ & $\begin{array}{c}\text { Baseline } \\
\text { Manic or Mixed Symptoms } \\
(\mathrm{n}=103)\end{array}$ \\
\hline \multicolumn{4}{|l|}{ Baseline demographic and clinical characteristics } \\
\hline \multicolumn{4}{|l|}{ Age, years } \\
\hline Mean (SD) & $38.6(11.4)$ & $41.0(11.5)$ & $37.2(11.2)$ \\
\hline Median (range) & $39(18-70)$ & $41(22-70)$ & $38(18-61)$ \\
\hline \multicolumn{4}{|l|}{ Gender, n (\%) } \\
\hline Male & $92(56.8)$ & $28(47.5)$ & $64(62.1)$ \\
\hline Female & $70(43.2)$ & $31(52.5)$ & $39(37.9)$ \\
\hline \multicolumn{4}{|l|}{ Race, n (\%) } \\
\hline Caucasian & $51(31.5)$ & $19(32.2)$ & $32(31.1)$ \\
\hline Hispanic & $3(1.9)$ & $2(3.4)$ & $1(1.0)$ \\
\hline Black & $18(11.1)$ & $5(8.5)$ & $13(12.6)$ \\
\hline Other (Indian) & $90(55.6)$ & $33(55.9)$ & $57(55.3)$ \\
\hline \multicolumn{4}{|l|}{ Bipolar disorder subtype, n(\%) } \\
\hline Type I & $144(88.9)$ & $48(81.4)$ & $96(93.2)$ \\
\hline Type ॥ & $18(11.1)$ & $11(18.6)$ & $7(6.8)$ \\
\hline \multicolumn{4}{|l|}{ Most recent episode, $\mathrm{n}(\%)$} \\
\hline Depressed & $56(34.6)$ & $44(74.6)$ & $12(11.7)$ \\
\hline Manic & $79(48.8)$ & $6(10.2)$ & $73(70.9)$ \\
\hline Mixed & $19(11.7)$ & $8(13.6)$ & $11(10.7)$ \\
\hline Hypomanic & $8(4.9)$ & $1(1.7)$ & $7(6.8)$ \\
\hline Time since most recent episode, weeks, mean (SD) & $6.0(4.6)$ & $6.1(4.8)$ & $5.9(4.5)$ \\
\hline \multicolumn{4}{|l|}{ Disposition } \\
\hline Completed OL phase & $120(74.1)$ & $44(74.6)$ & $76(73.8)$ \\
\hline Discontinued & $42(25.9)$ & $15(25.4)$ & $27(26.2)$ \\
\hline \multicolumn{4}{|l|}{ Reason for discontinuation } \\
\hline Withdrawal of consent & $14(8.6)$ & $7(11.9)$ & $7(6.8)$ \\
\hline AEs & $13(8.0)$ & $6(10.2)$ & $7(6.8)$ \\
\hline Lost to follow-up & $10(6.2)$ & $2(3.4)$ & $8(7.8)$ \\
\hline Nonadherent & $1(0.6)$ & $0(0)$ & $1(1.0)$ \\
\hline Other & $4(2.5)^{a}$ & $0(0)$ & $4(3.9)^{\mathrm{a}}$ \\
\hline \multicolumn{4}{|l|}{ RLAI mean daily dose and dose distribution } \\
\hline Dose, mg, mean (SD) & $27.9(5.6)$ & $26.5(4.1)$ & $28.6(6.2)$ \\
\hline \multicolumn{4}{|l|}{ Dose distribution, n (\%) } \\
\hline $25 \mathrm{mg}$ & $127(78.4)$ & $52(88.1)$ & $75(72.8)$ \\
\hline $37.5 \mathrm{mg}$ & $33(20.4)$ & $7(11.9)$ & $26(25.2)$ \\
\hline $50 \mathrm{mg}$ & $2(1.2)$ & $0(0)$ & $2(1.9)$ \\
\hline
\end{tabular}

$\mathrm{OL}$, open-label; RLAl, risperidone long-acting therapy; SD, standard deviation.

${ }^{a}$ Of these subjects, 3 discontinued because of lack of efficacy and 1 because of pregnancy.

was $2.5(3.8) \mathrm{kg}$ for subjects at LOCF end point and 2.7 (3.9) $\mathrm{kg}$ for completers ( $\mathrm{p}<.001 \mathrm{vs}$. baseline for both comparisons).

\section{Subjects with Manic/Mixed Symptoms at Baseline Efficacy}

The overall clinical status of subjects with manic/mixed symptoms at baseline also significantly improved, as seen in significant changes on the CGI-BP-S at each time point, again starting at Week 4, including LOCF end point (Figure 1). Remission was attained by $58.2 \%$ of subjects at LOCF end point and by $64.0 \%$ of completers (Figure 2). Mean YMRS scores decreased significantly at each time point, including LOCF end point (Figure 4). There was a small but significant improvement in MADRS scores for completers $(\mathrm{p}<.05)$. No significant improvement was observed in subjects at LOCF end point (Table 3). A 10-point improvement in GAF score was observed in $65.9 \%$ of subjects at LOCF end point and in $72.0 \%$ of subjects who completed the study, 
Table 2 Bipolar disorder medications (ITT population)

\begin{tabular}{|c|c|c|c|}
\hline \multicolumn{4}{|c|}{ OL Baseline } \\
\hline & $\begin{array}{c}\text { Total } \\
(\mathrm{N}=162)\end{array}$ & $\begin{array}{l}\text { Baseline } \\
\text { Depressive } \\
\text { Symptoms } \\
(\mathrm{n}=59)\end{array}$ & $\begin{array}{c}\text { Baseline } \\
\text { Manic/Mixed Symptoms } \\
(\mathrm{n}=103)\end{array}$ \\
\hline \multicolumn{4}{|c|}{ Number of bipolar medications ${ }^{\mathrm{a}, \mathrm{b}}$} \\
\hline 0 & $17(10.5)$ & $5(8.5)$ & $12(11.7)$ \\
\hline 1 & $37(22.8)$ & $14(23.7)$ & $23(22.3)$ \\
\hline 2 & $49(30.3)$ & $16(27.1)$ & $33(32.0)$ \\
\hline$\geq 3$ & $59(36.4)$ & $24(40.7)$ & $35(34.0)$ \\
\hline Mood stabilizers & $128(79.0)$ & $44(74.6)$ & $84(81.6)$ \\
\hline Antipsychotics & $47(29.0)$ & $17(28.8)$ & $30(29.1)$ \\
\hline Antidepressants & $48(29.6)$ & $26(44.1)$ & $22(21.4)$ \\
\hline Anxiolytics & $54(33.3)$ & $20(33.9)$ & $34(33.0)$ \\
\hline \multicolumn{4}{|c|}{ OL Week 16 (Completers) } \\
\hline & $\begin{array}{c}\text { Total } \\
(\mathrm{N}=120)\end{array}$ & $\begin{array}{l}\text { Baseline } \\
\text { Depressive } \\
\text { Symptoms } \\
(\mathrm{n}=44)\end{array}$ & $\begin{array}{c}\text { Baseline } \\
\text { Manic or Mixed Symptoms } \\
(n=76)\end{array}$ \\
\hline \multicolumn{4}{|c|}{ Number of bipolar disorder medications $\mathrm{s}^{\mathrm{a}, \mathrm{c}}$} \\
\hline 0 & $8(6.7)$ & $0(0)$ & $8(10.5)$ \\
\hline 1 & $41(34.2)$ & $16(36.4)$ & $25(32.9)$ \\
\hline 2 & $39(32.5)$ & 17 (38.6) & $22(29.0)$ \\
\hline$\geq 3$ & $32(26.7)$ & $11(25.0)$ & $21(27.6)$ \\
\hline Mood stabilizers & 99 (82.5) & 35 (79.6) & $64(84.2)$ \\
\hline Antidepressants & $51(42.5)$ & $28(63.6)$ & $23(30.3)$ \\
\hline Anxiolytics & $32(26.7)$ & $11(25.0)$ & $21(27.6)$ \\
\hline
\end{tabular}

ITT, intent to treat; OL, open-label.

${ }^{a}$ A subject taking $>1$ medication within a class and subclass was counted once within the class and subclass.

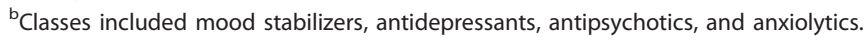

${ }^{c}$ Classes included mood stabilizers, antidepressants, and anxiolytics.

and the mean (SD) improvement from baseline in GAF scores was 18.4 (17.1) and $21.0(16.7)(\mathrm{p}<.001)$, respectively (Table 3 ).

\section{Safety}

At least $1 \mathrm{AE}$ was observed in $78.6 \%$ of subjects experiencing manic/mixed symptoms. The most common AEs with an incidence of $\geq 10 \%$ were tremor (26.2\%), muscle rigidity $(17.5 \%)$, weight increase $(17.5 \%)$, and sedation (11.7\%); $6.8 \%$ of subjects discontinued because of AEs. At baseline, the mean (SD) weight was 75.1 (20.0) kg. The mean (SD) weight increase from baseline was 1.8 (4.3) $\mathrm{kg}$ for subjects at LOCF end point and 1.8 (4.6) $\mathrm{kg}$ for completers $(\mathrm{p}<.01$ vs. baseline for both comparisons).

\section{Discussion}

The efficacy and safety of maintenance RLAI as monotherapy or adjunctive therapy in subjects with bipolar disorder have been confirmed in large, controlled studies $[15,16,21]$. However, the particular types of patients with bipolar disorder who might best be considered for this treatment have not been fully established. Data from this post hoc analysis suggest that patients with a history of frequent relapse who experience acute symptoms might benefit from the addition of RLAI to their current treatment regimen of mood stabilizers, antidepressants, and/or anxiolytics.

Because the data reported here represent a post hoc evaluation, these results are specific to the population studied here and may not be readily generalizable to the broader population of patients with bipolar disorder. A substantial proportion of subjects entered the relapse-prevention study with significant symptoms, despite receiving bipolar disorder medications at baseline. This may support the fact that this frequentlyrelapsing population is difficult to manage and has poor adherence to medication. The addition of adjunctive RLAI was associated with significant improvements in clinical status and symptoms by week 4 , as determined by the CGI-BP-S, YMRS, and MADRS scales. Remission was achieved in more than one-half of the total population by the 16-week LOCF end point and more than $60 \%$ had a 10 -point improvement on the GAF scale. 


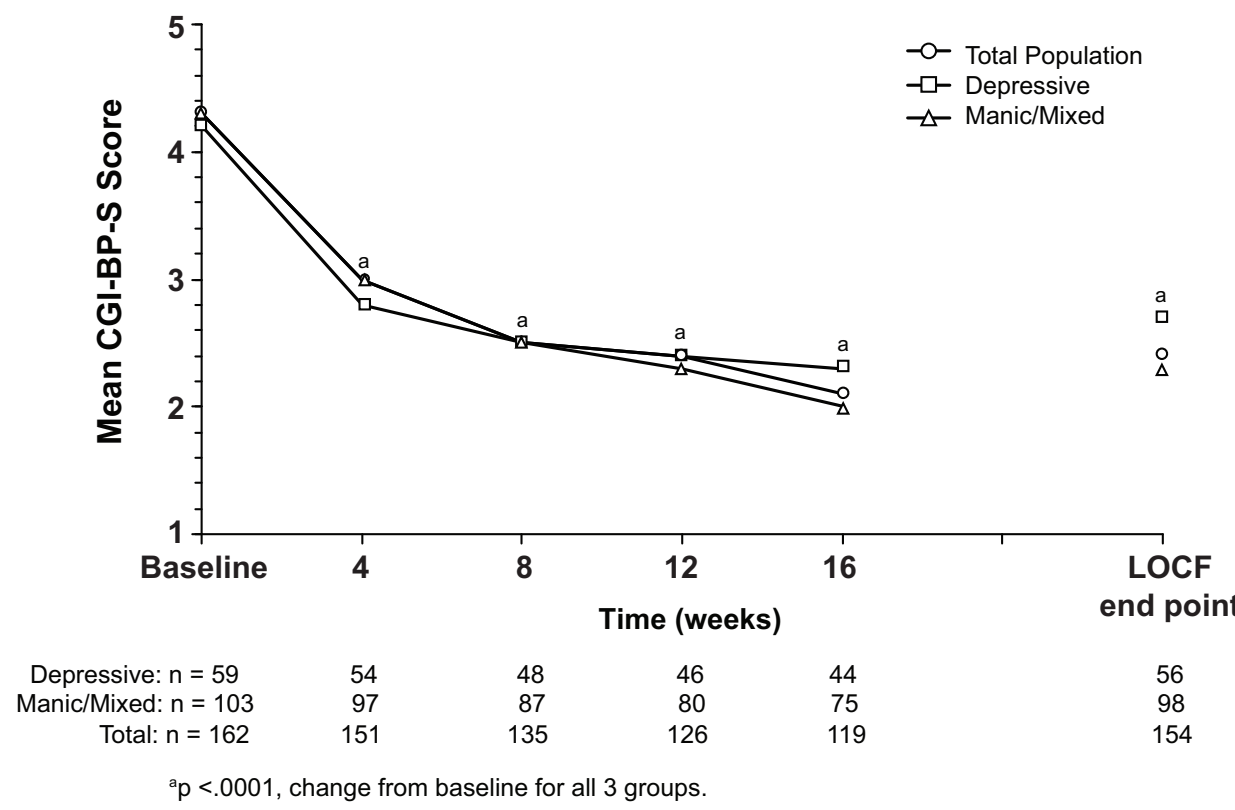

Figure 1 Mean CGI-BP-S score over time (ITT analysis set). CGI-BP-S, Clinical Global Impressions of Bipolar Disorder-Severity; LOCF, last observation carried forward.

Table 3 Efficacy measures: baseline and end point values in the open-label stabilization phase (ITT population)

\begin{tabular}{|c|c|c|c|}
\hline & $\begin{array}{c}\text { Total } \\
(\mathrm{N}=162)\end{array}$ & $\begin{array}{c}\text { Baseline } \\
\text { Depressive Symptoms } \\
(n=59)\end{array}$ & $\begin{array}{c}\text { Baseline } \\
\text { Manic or Mixed Symptoms } \\
(n=103)\end{array}$ \\
\hline \multicolumn{4}{|l|}{ CGI-BP-S, mean (SD) } \\
\hline Baseline & $4.3(0.8)$ & $4.2(0.8)$ & $4.3(0.8)$ \\
\hline \multicolumn{4}{|l|}{ Change from baseline } \\
\hline Completers $^{\mathrm{a}}$ & $-2.1(1.4)^{\mathrm{e}}$ & $-1.9(1.5)^{\mathrm{e}}$ & $-2.2(1.3)^{\mathrm{e}}$ \\
\hline LOCF end point ${ }^{\mathrm{b}}$ & $-1.8(1.5)^{\mathrm{e}}$ & $-1.5(1.6)^{\mathrm{e}}$ & $-2.0(1.5)^{\mathrm{e}}$ \\
\hline \multicolumn{4}{|l|}{ MADRS, mean (SD) } \\
\hline Baseline & $15.0(11.6)$ & $25.4(6.4)$ & $9.0(9.5)$ \\
\hline \multicolumn{4}{|l|}{ Change from baseline } \\
\hline Completers $^{\mathrm{a}}$ & $-7.2(11.2)^{\mathrm{e}}$ & $-15.6(10.7)^{e}$ & $-2.2(8.1)^{d}$ \\
\hline LOCF end point ${ }^{\mathrm{b}}$ & $-6.0(12.6)^{e}$ & $-14.0(11.2)^{\mathrm{e}}$ & $-1.4(11.0)$ \\
\hline \multicolumn{4}{|l|}{ YMRS, mean (SD) } \\
\hline Baseline & $18.8(12.1)$ & $5.8(4.5)$ & $26.3(8.2)$ \\
\hline \multicolumn{4}{|l|}{ Change from baseline } \\
\hline Completers $^{a}$ & $-14.2(12.5)^{\mathrm{e}}$ & $-2.3(5.5)^{d}$ & $-21.2(9.9)^{\mathrm{e}}$ \\
\hline LOCF end point ${ }^{\mathrm{b}}$ & $-13.2(13.8)^{\mathrm{e}}$ & $-0.9(8.6)$ & $-20.2(11.1)^{\mathrm{e}}$ \\
\hline \multicolumn{4}{|l|}{ GAF } \\
\hline \multicolumn{4}{|c|}{$\geq 10$-point improvement (\%) } \\
\hline Completers $^{\mathrm{a}}$ & 68.9 & 63.6 & 72.0 \\
\hline LOCF end point $^{c}$ & 62.3 & 56.4 & 65.9 \\
\hline Baseline, mean (SD) & $50.9(11.4)$ & $52.5(10.0)$ & $49.9(12.1)$ \\
\hline \multicolumn{4}{|c|}{ Change from baseline, mean (SD) } \\
\hline Completers $^{a}$ & $19.0(16.7)^{\mathrm{e}}$ & $15.5(16.4)^{\mathrm{e}}$ & $21.0(16.7)^{\mathrm{e}}$ \\
\hline LOCF end point ${ }^{c}$ & $16.3(17.1)^{\mathrm{e}}$ & $13.0(16.6)^{\mathrm{e}}$ & $18.4(17.1)^{\mathrm{e}}$ \\
\hline
\end{tabular}

CGI-BP-S, Clinical Global Impressions of Bipolar Disorder-Severity; GAF, Global Assessment of Functioning; ITT, intent to treat; LOCF, last observation carried forward; MADRS, Montgomery-Åsberg Depression Rating Scale; SD, standard deviation; YMRS, Young Mania Rating Scale.

${ }^{a} n=119, n=44$, and $n=75 ;{ }^{b} n=154, n=56$, and $n=98 ; ~ n=146, n=55$, and $n=91$ for the total, depressive, and manic/mixed populations, respectively. ${ }^{d} p<.05$ vs. baseline; ${ }^{e} p<.001$ vs. baseline. 


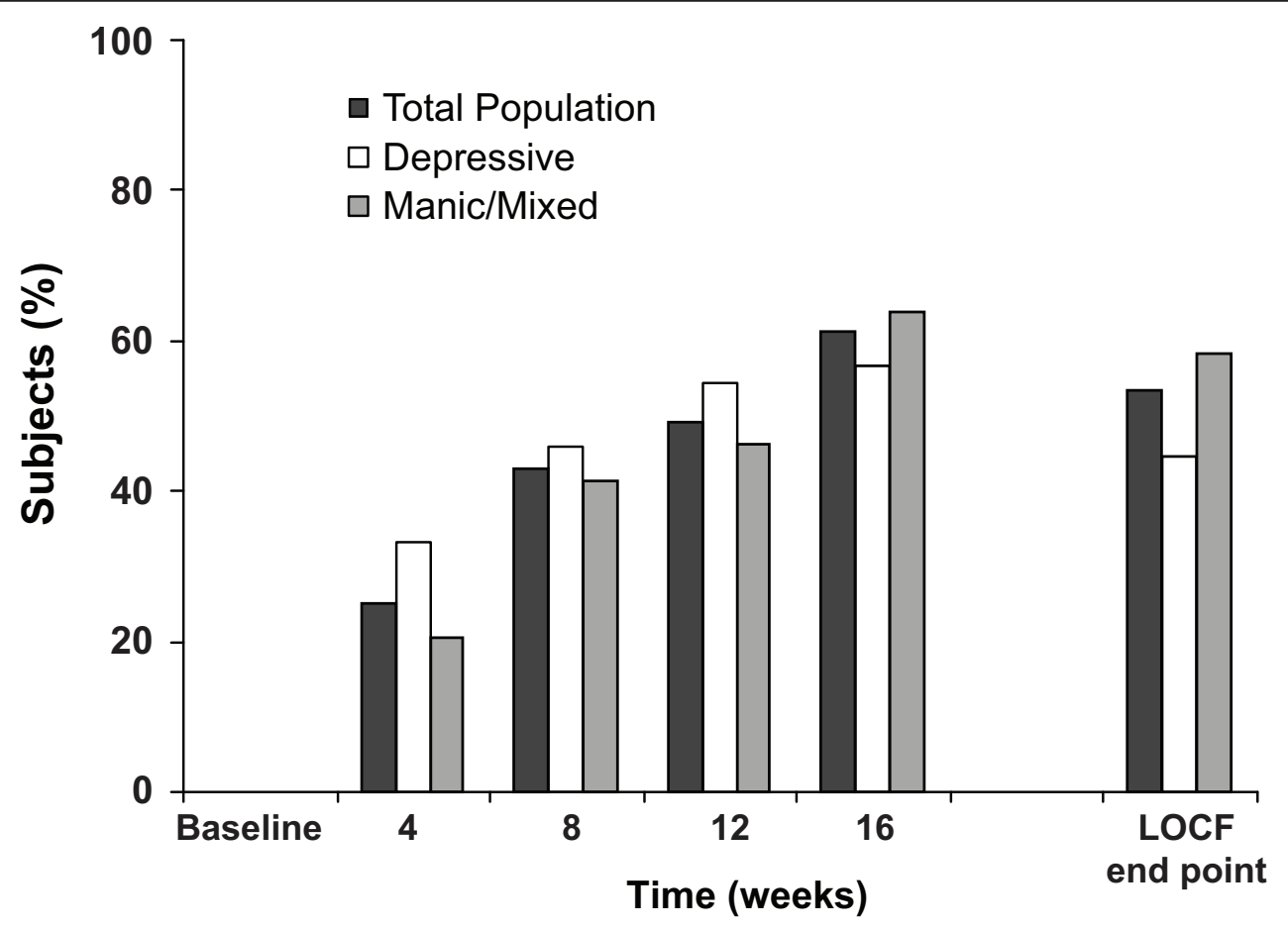

$\begin{array}{rrrrrr}\text { Depressive: } n=59 & 54 & 48 & 46 & 44 & 56 \\ \text { Manic/Mixed: } n=103 & 97 & 87 & 80 & 75 & 98 \\ \text { Total: } n=162 & 151 & 135 & 126 & 119 & 154\end{array}$

Figure 2 Point remission rates. LOCF, last observation carried forward (ITT analysis set).

Determining a medication's effectiveness in treating the manic and depressive symptoms of bipolar disorder is important for patient management. For subjects with manic/mixed symptoms, RLAI treatment resulted in clinical and symptom improvement within 4 weeks of treatment initiation with significant increases in remission rates and patient functioning. RLAI also was found to be effective in subjects with depressive symptoms. These patients are typically difficult to treat and are associated with poor functioning [22] and a high frequency of depressive episodes has been reported to be predictive of nonadherence [11]. In the current study, subjects with depressive symptoms showed significant clinical and symptom improvement by week 4 and a majority of subjects achieved remission. Also, more than half of the subjects with depressive and manic/mixed symptoms achieved a significant improvement in functioning. Although the analyses were not preplanned to analyze differences in efficacy/tolerability between these groups of subjects, these data may suggest that RLAI may be effective regardless of depressive or manic/mixed symptoms.

No unexpected safety or tolerability findings were identified, and AE rates were similar to those found in the overall study population [15]. This suggested that the tolerability profile may be independent of mood state or severity of symptoms. The mean weight of subjects increased by approximately $2 \mathrm{~kg}$, whether measured at study end point or at completion of all 16 weeks of treatment.

Although they suggest that RLAI is effective in patients with bipolar disorder who have frequent relapses, these results must be interpreted with caution. As a post hoc analysis of an open-label stabilization phase of a relapse-presentation, this study did not include a control group. Nonetheless, the efficacy results observed in this post hoc analysis with RLAI were generally similar to those of the open-label stabilization phase of the overall study [15]. Also, subject compliance with their individual treatment regimens of mood stabilizers, antidepressants, and/or anxiolytics before study entry was not established. Therefore, improvements seen in this analysis may be due in part to noncompliance with previous medications. Additionally, due to the release profile of RLAI ( $<1 \%$ of risperidone is released during the first 3 weeks) [23] oral supplementation with antipsychotics was required for the first 3 weeks of the study. This may have influenced the results at the earlier time points. However, by the week 4 assessment the 


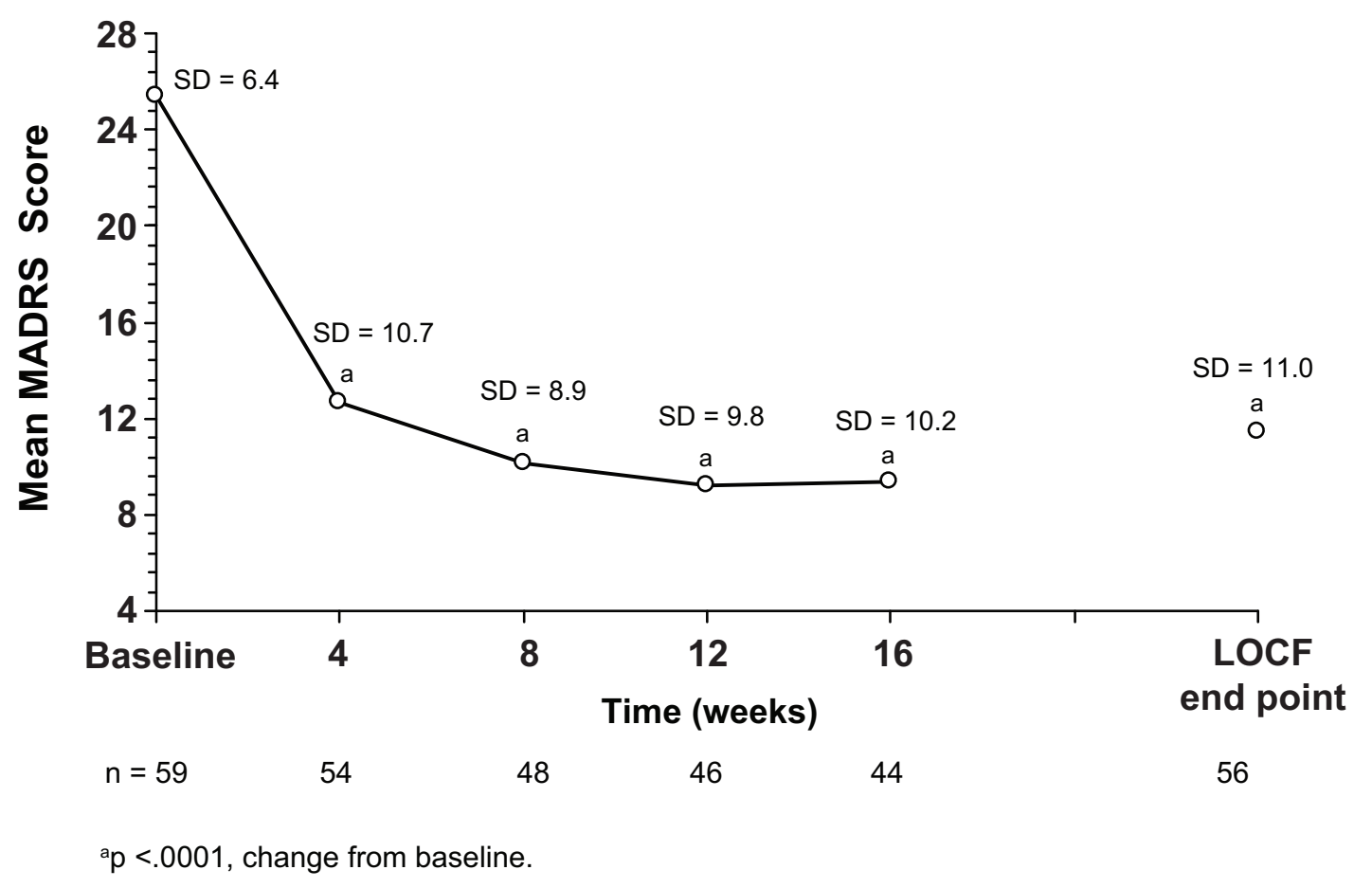

Figure 3 Mean MADRS scores for subjects with depressive symptoms at open-label baseline (ITT analysis set). MADRS, MontgomeryÅsberg Depression Rating Scale; LOCF, last observation carried forward; SD, standard deviation.

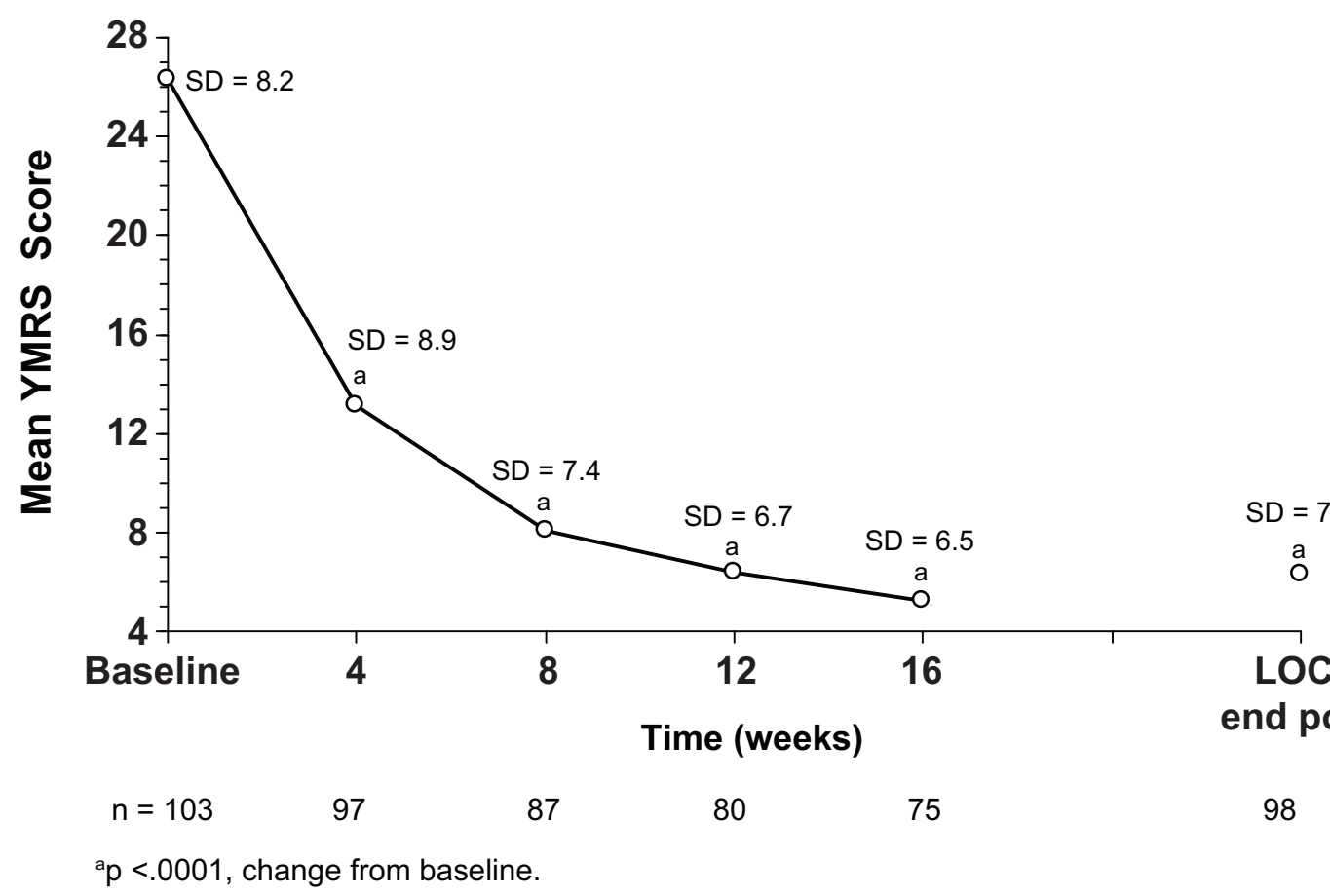

Figure 4 Mean YMRS scores for subjects with manic/mixed symptoms at open-label baseline (ITT analysis set). LOCF, last observation carried forward; SD, standard deviation; YMRS, Young Mania Rating Scale. 
main release of RLAI would have occurred per the prescribing information [23]. Remission was analyzed at each individual time point and did not account for a subject's remission status at previous time points during the open-label stabilization phase. Therefore, the percentage of subjects who met stable remission criteria could not be established. Nonetheless, over half of subjects met remission criteria by week 16. Although there may appear to be differences in onset of remission for the 2 subpopulations there were substantial betweengroup differences in baseline demographics, baseline disease characteristics, symptomatology, as well as the scales used to measure symptoms. While these data may be hypothesis-generating, the timing of improvement of symptom domains among these different subpopulations could not be established.

\section{Conclusions}

To summarize, in subjects with symptomatic bipolar disorder who experienced frequent relapses, significant improvements were observed with regard to mood symptoms, clinical status, and functioning, after the addition of RLAI to their current treatment regimen of mood stabilizers, antidepressants, and/or anxiolytics. Remission was achieved by approximately one-half of all subjects during 16 weeks of treatment, with improvement observed as early as 4 weeks. Benefits were observed in subjects with depressive symptoms or manic/mixed symptoms. The addition of RLAI, therefore, may be useful for adjunctive treatment in patients with bipolar disorder who continue to frequently experience symptoms despite previous and ongoing treatment.

\footnotetext{
Acknowledgements

This study was supported by funding from Janssen Scientific Affairs, LLC. Study Institutional Review Boards and Ethics Committees

USA

Coast IRB, LLC, San Clemente, California; Institutional Review Board - Medical Center, Cincinnati, Ohio; Western Institutional Review Board, Olympia, Washington; Sharp HealthCare, San Diego, California; UCI Institutional Review Board, Irvine, California; McLean Hospital Cognitive Neuroimaging Laboratory, Belmont, Massachusetts

India

SMS Medical College, Jaipur; KS Hegde Medical Academy, Deralkatte, Mangalore (D.K.); Asha Hospital, Institute of Medical Psychology Counselling \& Psychotherapy, Banjara Hills, Hyderabad; National Institute of Mental Health and Neurosciences, Bangalore; Madras Medical College \& Government General Hospital, Chennai; Kasturba Hospital Manipal, Karnataka; King George's Medical University, Lucknow; Dr. R.N. Cooper Municipal General Hospital, Mumbai; Government Medical College \& Chest Hospital, Mulankunnathukavu, Thrissur Kerala; St. John's Medical College Hospital, Bangalore; G.B. Pant Hospital, New Delhi; Post Graduate Institute of Medical Education and Research, Chandigarh; B.J. Medical College and Civil Hospital Ahmedabad; Lokmanya Tilak Municipal Medical College and Lokmanya Tilak Municipal General Hospital, Sion, Mumbai, Maharashtra; Sri Venkateswara Medical College, Tirupati; Madras Medical College \& Research Institute, Kilpauk, Chennai; VIMHANS Hospital, New Delhi; K.S. Hegde Medical Academy, Mangalore (D.K.).
}

The authors wish to acknowledge the contributions of Cynthia A. Bossie (employee of Janssen Scientific Affairs, LLC, Titusville, NJ, USA) in the development of this manuscript.

The authors also wish to acknowledge Matthew Grzywacz, PhD, Mariana Ovnic, PhD, and ApotheCom (funding supported by Janssen Scientific

Affairs, LLC, Titusville, NJ) in the development and submission of this article.

\section{Author details}

${ }^{1}$ Formerly, Janssen Scientific Affairs, LLC, Titusville, NJ, USA. ${ }^{2}$ University of Cincinnati College of Medicine, Cincinnati, OH, USA. ${ }^{3}$ Johnson \& Johnson Pharmaceutical Research and Development, LLC, Titusville, NJ, USA. ${ }^{4}$ Janssen Scientific Affairs, LLC, Titusville, NJ, USA.

\section{Authors' contributions}

WM, LA, IT, JTH, and NT contributed to the conception and design, acquisition of data, analysis and interpretation of data, and drafting of the manuscript and its critical revision for important intellectual content. CMA was involved in the interpretation of data and in the critical drafting and revising of the manuscript for important intellectual content. All authors read and approved the final manuscript.

\section{Competing interests}

At the time of this analysis, W Macfadden was a full-time employee of Janssen Scientific Affairs, LLC. L Alphs and N Turner are full-time employees of Janssen Scientific Affairs, LLC, and Johnson \& Johnson stockholders. JT Haskins and I Turkoz are full-time employees of Johnson \& Johnson Pharmaceutical Research and Development, LLC, and Johnson \& Johnson stockholders. CM Adler over the last 12 months has received honoraria for speaking and consulting from Merck, as well as research support from Abbott Laboratories, AstraZeneca, Eli Lilly, Shire, Johnson \& Johnson, Pfizer, Repligen, and Martek. With the exception of AstraZeneca, the research support has been in the form of payments for multisite clinical trials.

Received: 20 December 2010 Accepted: 28 October 2011

Published: 28 October 2011

\section{References}

1. Keck PE Jr, McElroy SL, Strakowski SM, West SA, Sax KW, Hawkins JM, Bourne ML, Haggard P: 12-month outcome of patients with bipolar disorder following hospitalization for a manic or mixed episode. Am J Psychiatry 1998, 155:646-652.

2. Judd LL, Akiskal HS: The prevalence and disability of bipolar spectrum disorders in the US population: re-analysis of the ECA database taking into account subthreshold cases. J Affect Discord 2003, 73:123-131.

3. Bowden CL: Bipolar disorder and work loss. Am J Manag Care 2005, 11: S91-S94.

4. Kessler RC, Akiskal HS, Ames M, Birnbaum H, Greenberg P, Hirschfeld RM, Jin R, Merikangas KR, Simon GE, Wang PS: Prevalence and effects of mood disorders on work performance in a nationally representative sample of U.S. workers. Am J Psychiatry 2006, 163:1561-1568.

5. Laxman KE, Lovibond KS, Hassan MK: Impact of bipolar disorder in employed populations. Am J Manag Care 2008, 14:757-764.

6. Hirschfeld RMA, Bowden CL, Gitlin MJ, Keck PE, Suppes T, Thase ME, Wagner KD, Perlis RH: Practice Guideline for the Treatment of Patients With Bipolar Disorder., Second 2002, 1-82.

7. Coryell W: Rapid cycling bipolar disorder: clinical characteristics and treatment options. CNS Drugs 2005, 19:557-569.

8. Baldessarini RJ, Tondo L, Floris G, Hennen J: Effects of rapid cycling on response to lithium maintenance treatment in 360 bipolar I and II disorder patients. J Affect Discord 2000, 61:13-22.

9. Perlis RH, Ostacher MJ, Miklowitz DJ, Hay A, Nierenberg AA, Thase ME, Sachs GS: Clinical features associated with poor pharmacologic adherence in bipolar disorder: results from the STEP-BD study. J Clin Psychiatry 2010, 71:296-303.

10. Martinez-Aran A, Scott J, Colom F, Torrent C, Tabares-Seisdedos R, Daban C, Leboyer M, Henry C, Goodwin GM, Gonzalez-Pinto A, Cruz N, SanchezMoreno J, Vieta E: Treatment nonadherence and neurocognitive impairment in bipolar disorder. J Clin Psychiatry 2009, 70:1017-1023.

11. Gutierrez-Rojas L, Jurado D, Martinez-Ortega JM, Gurpegui M: Poor adherence to treatment associated with a high recurrence in a bipolar disorder outpatient sample. J Affect Discord 2010, 127:77-83. 
12. Hassan M, Lage MJ: Risk of rehospitalization among bipolar disorder patients who are nonadherent to antipsychotic therapy after hospital discharge. Am J Health-Syst Pharm 2009, 66:358-365.

13. Kane JM: Dosing issues and depot medication in the maintenance treatment of schizophrenia. Int Clin Psychopharmacol 1995, 10:65-71.

14. Vieta E, Nieto E, Autet A, Rosa AR, Goikolea JM, Cruz N, Bonet P: A longterm prospective study on the outcome of bipolar patients treated with long-acting injectable risperidone. World J Biol Psychiatry 2008, 9:219-224.

15. Macfadden W, Alphs L, Haskins JT, Turner N, Turkoz I, Bossie C, Kujawa M, Mahmoud R: A randomized, double-blind, placebo-controlled study of maintenance treatment with adjunctive risperidone long-acting therapy in patients with bipolar I disorder who relapse frequently. Bipolar Dis 2009, 11:827-839.

16. Quiroz JA, Yatham LN, Palumbo JM, Karcher K, Kushner S, Kusumakar V: Risperidone long-acting injectable monotherapy in the maintenance treatment of bipolar I disorder. Biol Psychiatry 2010, 68:156-162.

17. Montgomery SA, Asberg M: A new depression scale designed to be sensitive to change. Br J Psychiatry 1979, 134:382-389.

18. Young RC, Biggs JT, Ziegler VE, Meyer DA: A rating scale for mania: reliability, validity and sensitivity. Br J Psychiatry 1978, 133:429-435

19. Spearing MK, Post RM, Leverich GS, Brandt D, Nolen W: Modification of the Clinical Global Impressions (CGI) scale for use in bipolar illness (BP): the CGI-BP. Psychiatry Res 1997, 73:159-171.

20. Jones SH, Thornicroft G, Coffey M, Dunn G: A brief mental health outcome scale-reliability and validity of the Global Assessment of Functioning (GAF). Br J Psychiatry 1995, 166:654-659.

21. Montgomery S, Vieta E, Sulaiman AH, Cordoba R, Huberlant B, Schreiner A, Martinez G: Randomized, double-blind, placebo-controlled study of risperidone long-acting injectable in relapse prevention in patients with bipolar I disorder. Presented at the European Psychiatric Association 18th European Congress of Psychiatry, Munich, Germany 2010.

22. Rosa AR, Reinares M, Michalak EE, Bonnin CM, Sole B, Franco C, Comes M, Torrent C, Kapczinski F, Vieta E: Functional impairment and disability across mood states in bipolar disorder. Value Health 2010.

23. Riperda ${ }^{\circledR}$ Consta ${ }^{\circledR}$ [prescribing information]. Titusville, NJ: Ortho-McNeil Janssen; 2010.

\section{Pre-publication history}

The pre-publication history for this paper can be accessed here: http://www.biomedcentral.com/1471-244X/11/171/prepub

\section{Submit your next manuscript to BioMed Central and take full advantage of:}

- Convenient online submission

- Thorough peer review

- No space constraints or color figure charges

- Immediate publication on acceptance

- Inclusion in PubMed, CAS, Scopus and Google Scholar

- Research which is freely available for redistribution

Submit your manuscript at www.biomedcentral.com/submit
Biomed Central 